\title{
Spectrophotometric Studies of the Interaction of Noble Metals with Quercetin and Quercetin-5'-Sulfonic Acid
}

\author{
Maria BalcerzaK, *† Maria KopaCz,** Anna KosioreK,* Elzbieta SwIECICKA,* \\ and Stanisław Kus* \\ *Department of Analytical Chemistry, Warsaw University of Technology, Noakowskiego 3, \\ 00-664 Warsaw, Poland \\ **Department of Inorganic and Analytical Chemistry, Rzeszow University of Technology, \\ 35-959 Rzeszow, Poland
}

\begin{abstract}
Results of some studies on the interaction of noble metals with quercetin (Q) and quercetin-5'-sulfonic acid (QSA), the compounds of flavonoid group, are presented. The reactions of chloride complexes of the metals: $\mathrm{RuOHCl}_{5}^{2-}, \mathrm{PdCl}_{4}{ }^{2-}$, $\mathrm{OsCl}_{6}{ }^{2-}, \mathrm{PtCl}_{6}{ }^{2-}$ and $\mathrm{AuCl}_{4}{ }^{-}$with both reagents were examined. The redox reactions of ruthenium and gold with $\mathrm{Q}$ and QSA have been identified. The reaction of the metals with both reagents results in the formation of the oxidized form of Q that exhibits maximum absorbance at $291 \mathrm{~nm}$. Ruthenium and gold react with the examined reagents under similar conditions: $0.04 \mathrm{M} \mathrm{HCl}$ and $1 \times 10^{-4} \mathrm{M} \mathrm{Q}$ (or QSA). The $\mathrm{CH}_{3} \mathrm{OH}+\mathrm{H}_{2} \mathrm{O}(1: 1)(\mathrm{Q})$ and pure aqueous (QSA) media can be used. The reaction of gold with $\mathrm{Q}$ is slow at room temperature. It can be accelerated by heating the solution being examined. The reaction proceeds significantly faster when the water-soluble sulfonic derivative of quercetin, quercetin$5^{\prime}$-sulfonic acid, is used as a reagent. The new species formed can make the basis of spectrophotometric methods for the determination of ruthenium and gold. The molar absorptivities at $291 \mathrm{~nm}$ are equal to $5.0 \times 10^{3}$ and $2.2 \times 10^{4} \mathrm{~L} \mathrm{~mol}^{-1}$ $\mathrm{cm}^{-1}$ for $\mathrm{Ru}$ and $\mathrm{Au}$, respectively, independently of the reagent used. Some methods for the determination of the content of gold $(0.04 \%)$ in a cosmetic cream were developed.
\end{abstract}

(Received April 12, 2004; Accepted June 30, 2004)

\section{Introduction}

Quercetin belongs to a large group of naturally-occurring flavonoid compounds found in plants, foods and beverages. Flavonoids represent a sub-group of intensely colored polyphenolic phytochemicals. They contribute to plant color, providing a spectrum of colors from red to blue in flowers, fruit and leaves. ${ }^{1}$ Due to some interesting health-benefiting properties, flavonoids are widely examined in terms of chemistry as well as biological activity. The antioxidant, antitumor and antibacterial activity of flavonoids focuses the attention of many researchers in pharmaceutical and medicine chemistry. ${ }^{2}$

Flavonoids can also act as metal chelators. Their ability to form complexes with some $\mathrm{p}-, \mathrm{d}$ - and f-electron metals makes them interesting analytical reagents. ${ }^{3}$ Spectrophotometric and fluorometric detection techniques are most often used for the detection of metals bound to flavonoid ligands. Quercetin ${ }^{4-8}$ and morin $^{5,9-17}$ are most widely used in analytical procedures for the determination of various metals, e.g. $\mathrm{Al},{ }^{8,11,17} \mathrm{Cr},{ }^{4,5} \mathrm{~W},{ }^{5} \mathrm{Zr},{ }^{8} \mathrm{Ti},{ }^{13}$ $\mathrm{Fe},{ }^{12}$ and $\mathrm{Mo}^{9,12}$ by UV-VIS spectrophotometry and $\mathrm{Al},{ }^{14-16}$ $\mathrm{Zr},{ }^{6,10} \mathrm{Hf}^{6}$ and $\mathrm{Ge}^{7}$ using the fluorometric detection. Immobilized quercetin and morin served as solid-phase reagents for sorption and preconcentration of $\mathrm{Zr},{ }^{18,19} \mathrm{Sn},{ }^{18,20} \mathrm{Al},{ }^{21} \mathrm{Be}^{21,22}$ and Mo. ${ }^{23}$

This paper presents the first investigations of interactions of

† To whom correspondence should be addressed.

E-mail: mbal@ch.pw.edu.pl quercetin $(\mathrm{Q})$ and its sulfonate derivative, quercetin-5' ${ }^{\prime}$-sulfonic acid (QSA), with noble metals (ruthenium, palladium, osmium, platinum and gold). Till now, there has been no evidence (no literature data) about the interaction of flavonoids with noble metals. Chloride complexes of the metals were used in the experiments carried out in the work. Quercetin- $5^{\prime}$-sulfonic acid, contrary to quercetin, is a water-soluble compound. ${ }^{24}$ Similarly to quercetin, it forms complexes with some metals. The formation and properties of lanthanides complexes with QSA have recently been examined..$^{25-27}$

\section{Experimental}

\section{Apparatus}

Spectrophotometric measurements were made with a JASCO V-560 (Japan) UV-VIS spectrophotometer. Quartz cells $(1 \mathrm{~cm})$ were used.

\section{Reagents}

A ruthenium standard solution $\left(1 \mathrm{mg} \mathrm{ml}^{-1} \mathrm{Ru}\right)$ was prepared by fusion of $0.1000 \mathrm{~g}$ of powdered ruthenium in a silver crucible with $1 \mathrm{~g}$ of sodium peroxide. The temperature was gradually increased to a dark red glow $\left(\mathrm{ca} .450^{\circ} \mathrm{C}\right)$ and maintained for $10 \mathrm{~min}$. The sample was allowed to cool then dissolved in water and acidified with $\mathrm{HCl}$ to $1 \mathrm{M}$ concentration. The mixture was heated and the coagulated $\mathrm{AgCl}$ was filtered off. The filtrate was transformed into a $100-\mathrm{ml}$ standard flask and diluted to volume with $1 \mathrm{M} \mathrm{HCl}$. 
A palladium standard solution $\left(0.5910 \mathrm{mg} \mathrm{ml}^{-1} \mathrm{Pd}\right)$ was prepared by dissolving $5.0 \mathrm{~g}$ of palladium(II) chloride in $500 \mathrm{ml}$ of $1 \mathrm{M} \mathrm{HCl}$. The exact concentration of palladium in the obtained solution was determined by a gravimetric method using dimethylglyoxime as a precipitation reagent. Working solutions were obtained by appropriate dilution of the standard.

An osmium standard solution $\left(1 \mathrm{mg} \mathrm{ml}^{-1} \mathrm{Os}\right)$ was prepared by dissolving $0.2529 \mathrm{~g}$ of potassium hexachloroosmate $\left(\mathrm{K}_{2} \mathrm{OsCl}_{6}\right)$ in $100 \mathrm{ml} 1 \mathrm{M} \mathrm{HCl}$.

A platinum standard solution $\left(1 \mathrm{mg} \mathrm{ml}^{-1} \mathrm{Pt}\right)$ was prepared by dissolving $0.1000 \mathrm{~g}$ of platinum (99.99\% Pt wire) in $8 \mathrm{ml}$ of aqua regia. The obtained solution was evaporated nearly to dryness, then $3 \mathrm{ml}$ of conc. $\mathrm{HCl}$ was added and the solution was again evaporated. The residue was dissolved in $1 \mathrm{M} \mathrm{HCl}$ and diluted to volume with this acid in a 100-ml standard flask.

A gold standard solution (1.141 $\mathrm{mg} \mathrm{ml}^{-1} \mathrm{Au}$ ) was prepared by dissolving $0.1141 \mathrm{~g}$ of metallic gold (99.99\% Au wire) in $4 \mathrm{ml}$ of aqua regia. The obtained solution was evaporated nearly to dryness, then $3 \mathrm{ml}$ conc. $\mathrm{HCl}$ was added and the solution was again evaporated. The residue was dissolved in $1 \mathrm{M} \mathrm{HCl}$ and diluted to volume with this acid in a 100-ml standard flask.

A quercetin standard solution, $1 \times 10^{-3} \mathrm{M}$, was prepared by dissolving $0.0338 \mathrm{~g}$ of the 3,3',4',5,7-pentahydroxyflavone $2 \mathrm{H}_{2} \mathrm{O}$ (Sigma) in $100 \mathrm{ml}$ of methanol.

A quercetin-5'-sulfonic acid (QSA), $1 \times 10^{-3} \mathrm{M}$ aqueous solution, was prepared by dissolving $0.0472 \mathrm{~g}$ of the reagent in $100 \mathrm{ml}$ of $\mathrm{H}_{2} \mathrm{O}$. The reagent was obtained according to the procedure described earlier. ${ }^{24}$

\section{Procedures}

The determination of gold (or ruthenium) with quercetin. The test solution containing not more than $120 \mu \mathrm{g}$ Au (or $300 \mu \mathrm{g}$ $\mathrm{Ru}$ ) was transferred into a $10-\mathrm{ml}$ standard flask. Then $1 \mathrm{ml} 1 \times$ $10^{-3} \mathrm{M}$ solution of quercetin and $4 \mathrm{ml}$ of methanol were added. The acidity of the sample was adjusted to $0.04 \mathrm{M} \mathrm{HCl}$. The sample was diluted to the mark with $0.001 \mathrm{M} \mathrm{HCl}$. For the determination of gold, the sample was heated at $70^{\circ} \mathrm{C}$ for 30 min, then cooled prior to submitting to a spectrophotometric measurement. The detection of ruthenium was performed directly after mixing the reagents. The spectrum of the solution was recorded against the blank at the following instrumental parameters: interpoint distance $0.2 \mathrm{~nm}$, scan speed $100 \mathrm{~nm}$ $\mathrm{min}^{-1}, 1 \mathrm{~s}$ integration time and $200-600 \mathrm{~nm}$ wavelength range. The concentration of gold (or ruthenium) was determined using the absorbance at $291 \mathrm{~nm}$ and the appropriate regression equation.

The determination of gold (or ruthenium) with quercetin-5'sulfonic acid. The test solution containing not more than 120 $\mu \mathrm{g} \mathrm{Au}$ (or $300 \mu \mathrm{g} \mathrm{Ru}$ ) was transferred into a 10-ml standard flask. Then $1 \mathrm{ml} 1 \times 10^{-3} \mathrm{M}$ QSA and hydrochloric acid were added in such amount as to obtain $0.04 \mathrm{M} \mathrm{HCl}$ in the final volume of the sample. The spectrum of the solution was recorded against the blank after $20 \mathrm{~min}$ in case of the determination of $\mathrm{Au}$, or directly after mixing the reagents in case of the determination of $\mathrm{Ru}$. Instrumental parameters similar to those given above for the procedure with the use of quercetin were employed. The concentration of gold (or ruthenium) was determined using the absorbance at $291 \mathrm{~nm}$ and the appropriate regression equation.

\section{Results and Discussion}

The interactions of chloride complexes of ruthenium $\left(\mathrm{RuOHCl}_{5}^{2-}\right)$, palladium $\left(\mathrm{PdCl}_{4}{ }^{2-}\right)$, osmium $\left(\mathrm{OsCl}_{6}{ }^{2-}\right)$, platinum

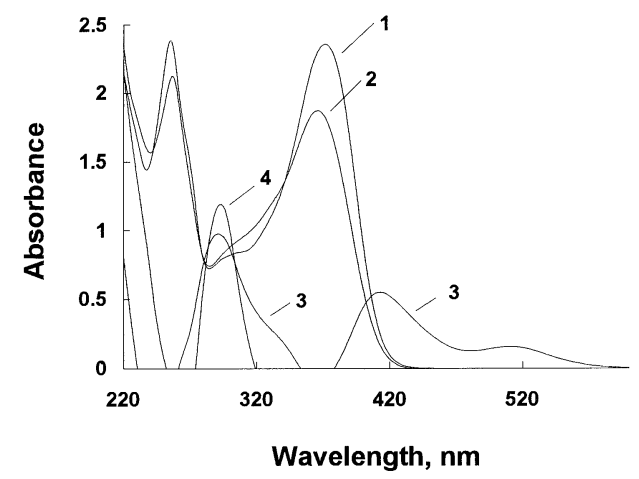

Fig. 1 UV-VIS spectra of Q (curve 1), QSA (curve 2); the product of the reaction of $\mathrm{Ru}(\mathrm{IV})\left(20 \mu \mathrm{g} \mathrm{ml}{ }^{-1} \mathrm{Ru}\right)$ with $\mathrm{Q}$ (curve 3) and $\mathrm{Au}$ (III) $\left(10 \mu \mathrm{g} \mathrm{ml}^{-1} \mathrm{Au}\right)$ with QSA (curve 4). $0.04 \mathrm{M} \mathrm{HCl}, 1 \times 10^{-4}$ M Q (QSA): curves 1 and 3, $\mathrm{CH}_{3} \mathrm{OH}: \mathrm{H}_{2} \mathrm{O}$ (1:1) solutions; curves 2 and 4 , aqueous solutions.

$\left(\mathrm{PtCl}_{6}{ }^{2-}\right)$ and gold $\left(\mathrm{AuCl}_{4}^{-}\right)$with quercetin and quercetin-5'sulfonic acid have been examined. Chloride complexes are the products of the majority of procedures applied for the digestion of various noble metal samples. ${ }^{28}$ They are widely used for the separation and the determination of the metals. ${ }^{29,30}$ The complexes chosen for the experiments carried out in this work have the highest stability in chloride media.

The interaction of particular metals with quercetin has been examined in methanolic-aqueous solutions, owing to the limited solubility of the reagent in water. Quercetin easily dissolves in methanol. Once dissolved, it occurs in soluble form in mixed methanolic-aqueous solutions up to $1: 4 \quad\left(\mathrm{CH}_{3} \mathrm{OH}: \mathrm{H}_{2} \mathrm{O}\right)$ volumetric ratio as examined in this work. Absorption spectrum of quercetin in the medium of methanolic-aqueous $(0.04 \mathrm{M}$ $\mathrm{HCl})(1: 1)$ solution used in the paper is shown in Fig. 1 (curve 1). Molar absorptivities corresponding to maximum absorption bands of the reagent equal to $2.38 \times 10^{4}$ (at $255 \mathrm{~nm}$ ) and $2.36 \times$ $10^{4}$ (at $371 \mathrm{~nm}$ ) L mol-1 $\mathrm{cm}^{-1}$. Methanolic-aqueous (1:1) solutions of quercetin are stable during long time periods (2 months as examined in this work). No changes in the spectrum of the reagent were observed when acidifying the solution even up to $2 \mathrm{M} \mathrm{HCl}$.

Quercetin-5'-sulfonic acid is easily soluble in water. The absorption spectrum of QSA in $0.04 \mathrm{M} \mathrm{HCl}$ is presented in Fig. 1 (curve 2). Molar absorptivities at two maximum absorption bands, 257 and $366 \mathrm{~nm}$, are equal to $2.12 \times 10^{4}$ and $1.83 \times 10^{4} \mathrm{~L}$ $\mathrm{mol}^{-1} \mathrm{~cm}^{-1}$, respectively. The aqueous solution of QSA is also stable. No changes in the spectrum of the reagent were observed within 2 months. The interaction of QSA with the metals was examined in pure aqueous solutions.

The experiments have shown that in chloride media only ruthenium and gold react with both examined reagents. No interaction of the other metals was observed under the conditions used. Studies on the reaction of quercetin and quercetin-5'-sulfonic acid with ruthenium and gold are described in the paper in detail.

The interaction of ruthenium with quercetin and quercetin-5'sulfonic acid

The experiments have shown that the reaction of $\mathrm{Ru}(\mathrm{IV})$ with quercetin results in the formation of a new species exhibiting a stable absorption band at $291 \mathrm{~nm}$ and two absorption bands at $412 \mathrm{~nm}$ and $510 \mathrm{~nm}$ (Fig. 1, curve 3). The absorption bands at $412 \mathrm{~nm}$ and $510 \mathrm{~nm}$ were identified in solutions at $0.01-0.1 \mathrm{M}$ $\mathrm{HCl}$ concentration. They probably belong to a ruthenium- 
Table 1 Statistical data of the results of the determination of ruthenium with quercetin and quercetin-5'-sulfonic acid

\begin{tabular}{|c|c|c|c|c|}
\hline \multicolumn{2}{|c|}{ 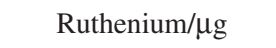 } & \multirow{2}{*}{$\begin{array}{c}\text { Standard } \\
\text { deviation/ } \\
\mu \mathrm{g}\end{array}$} & \multirow{2}{*}{$\begin{array}{c}\text { Relative } \\
\text { standard } \\
\text { deviation, \% }\end{array}$} & \multirow{2}{*}{ 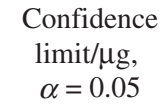 } \\
\hline Added & Determined $^{a}$ & & & \\
\hline \multicolumn{5}{|l|}{ Q } \\
\hline 20.00 & 19.72 & 1.07 & 5.42 & $19.72 \pm 1.12$ \\
\hline 100.00 & 100.52 & 4.48 & 4.45 & $100.52 \pm 4.70$ \\
\hline 200.00 & 202.97 & 2.99 & 1.47 & $202.97 \pm 3.14$ \\
\hline \multicolumn{5}{|l|}{ QSA } \\
\hline 20.00 & 19.46 & 1.13 & 5.82 & $19.46 \pm 1.19$ \\
\hline 100.00 & 100.42 & 4.39 & 4.37 & $100.42 \pm 4.61$ \\
\hline 200.00 & 200.05 & 3.10 & 1.55 & $200.05 \pm 3.25$ \\
\hline
\end{tabular}

a. $n=6$.

quercetin complex formed under the conditions used. The absorption band at $291 \mathrm{~nm}$ corresponds to the oxidized form of quercetin. Such a form was reported earlier as a product of the reaction of quercetin with $\mathrm{Fe}(\mathrm{III}) .^{31,32}$ It was identified as ortoquinone, the product of the redox reaction occurring between $\mathrm{Fe}$ (III) and quercetin. Some experiments have shown that quercetin is converted into a similar form under the action of $\mathrm{Ru}(\mathrm{IV})$. Ruthenium in chloride solutions can exist at various oxidation states. ${ }^{33}$ The reduction of $\mathrm{Ru}(\mathrm{IV})$ to $\mathrm{Ru}(\mathrm{III})$ and $\mathrm{Ru}$ (II) can easily occur in hydrochloric acid medium in the presence of a reduction agent. The molar absorptivities corresponding to the maximum absorption of the reaction products of quercetin with ruthenium amount to $5.0 \times 10^{3}, 2.8 \times$ $10^{3}$ and $1.0 \times 10^{3} \mathrm{~L} \mathrm{~mol}^{-1} \mathrm{~cm}^{-1}$ at 291,412 and $510 \mathrm{~nm}$, respectively.

The stability of the oxidized form of quercetin $\left(\lambda_{\max }\right.$ at 291 $\mathrm{nm}$ ) is higher than that of the maximum absorbance at 412 and $510 \mathrm{~nm}$. No changes in the spectrum of orto-quinone were observed within $48 \mathrm{~h}$. The temperature up to $70^{\circ} \mathrm{C}$ does not affect the absorbance of that form. No effect on the spectrum was observed when changing the amount of methanol introduced into the examined solution in the range from 1:4 to $4: 1\left(\mathrm{CH}_{3} \mathrm{OH}: \mathrm{H}_{2} \mathrm{O}\right)$. The ruthenium-quercetin complex $\left(\lambda_{\max }\right.$ at 412 and $510 \mathrm{~nm}$ ) exhibits significantly lower stability. A decrease of $10 \%$ within $2 \mathrm{~h}$ and of a further $10 \%$ within $24 \mathrm{~h}$ in maximum absorbance at $412 \mathrm{~nm}$ was observed at room temperature. Heating the solution results in rapid decomposition of the complex.

The reaction of ruthenium with quercetin occurs directly after mixing the reagents. Quercetin at $1 \times 10^{-4} \mathrm{M}$ in methanolic-aqueous (1:1) solution was found optimum for the experiments carried out in this work.

The amount of the generated oxidized form of quercetin corresponds to the concentration of ruthenium in the examined solution. This amount can make the basis of a method for the determination of ruthenium. The solutions containing the product of the reaction of $\mathrm{Ru}(\mathrm{IV})$ with quercetin obey Beer's law up to $30 \mu \mathrm{g} \mathrm{ml}^{-1} \mathrm{Ru}$. The calibration curve equation for the determination of ruthenium is: $y=0.0547 c-0.0059$, where $y$ is the absorbance and $c$ is the concentration of ruthenium. The correlation coefficient amounts to 0.9993 . The RSDs of the results of the determination of ruthenium were in the range of $1.47-5.42 \%$ (Table 1). The detection limit evaluated as triple standard deviation of the procedure blank $(n=6)$ and sensitivities in a standard calibration solution (DL $=$ 3SD/sensitivity) equal to $0.11 \mu \mathrm{g} \mathrm{ml}^{-1} \mathrm{Ru}$.

The experiments have shown that similar reaction products are obtained when quercetin is replaced by QSA. Quercetin-5'- sulfonic acid is easily soluble in water and this allows one to carry out the experiments in pure aqueous solutions. The oxidized form of QSA, being the product of the examined reaction, is the same as the one obtained when using quercetin as a reagent $\left(\lambda_{\max }\right.$ at $\left.291, \varepsilon=5.0 \times 10^{3} \mathrm{~L} \mathrm{~mol}^{-1} \mathrm{~cm}^{-1}\right)$. The use of QSA for the determination of ruthenium has also been examined here. The linearity of the calibration curve corresponds to a similar concentration range of ruthenium when using $\mathrm{Q}$ as a reagent. The regression equation for the determination of ruthenium with QSA is: $y=0.0477 c-0.0062$, where $y$ is the absorbance and $c$ is the concentration of ruthenium $\left(R^{2}=0.9997, \mathrm{RSD}\right.$ is within the range of $1.55-$ $5.82 \%$ (Table 1)).

The sensitivity of the determination of ruthenium, expressed by the value of molar absorptivity $(\varepsilon)$ reached in the examined systems with the use of Q or QSA, exceeds the sensitivity offered by some widely used methods, e.g. with thiourea and tin(II) chloride $\left(\varepsilon=2.5-2.9 \times 10^{3}\right.$ and $2.7 \times 10^{3} \mathrm{~L} \mathrm{~mol}^{-1} \mathrm{~cm}^{-1}$, respectively). ${ }^{30,33}$

\section{The interaction of gold with quercetin and quercetin- $5^{\prime}$-sulfonic} acid

The experiments have shown that redox reactions take place when $\mathrm{Au}(\mathrm{III})$ is introduced into the solution of quercetin or quercetin- $5^{\prime}$-sulfonic acid. In the case of gold, the form exhibiting the maximum absorbance at $291 \mathrm{~nm}$ is the only product of the examined reactions (Fig. 1, curve 4).

The reaction of gold with quercetin proceeds significantly slower as compared with the speed of the reaction using $\mathrm{Ru}(\mathrm{IV})$ as an oxidant. In methanolic-aqueous (1:1) solution, the oxidized form of quercetin, being the product of its reaction with $\mathrm{Au}(\mathrm{III})$, is quantitatively produced within $24 \mathrm{~h}$. No changes in the spectrum of the examined solution have been observed over the next $72 \mathrm{~h}$. It has been found that the reaction occurs significantly faster at higher temperatures. Heating the solution at $50^{\circ} \mathrm{C}$ allows one to reach the maximum absorbance at $291 \mathrm{~nm}$ within $60 \mathrm{~min}$. The increase in temperature results in a shorter reaction time, e.g. $30 \mathrm{~min}$ at $70^{\circ} \mathrm{C}$. The examined redox reaction proceeds significantly faster when QSA is used as a reagent. The quantitative conversion of this reagent into the same product as was obtained in the case of quercetin is observed within $20 \mathrm{~min}$ at room temperature. Hydrochloric acid concentration in the range of $0.006-0.05 \mathrm{M}$ has no effect on the reaction examined. The concentration of $1 \times 10^{-4} \mathrm{M}$ QSA has been used in the experiments carried out in this work.

Both systems, $\mathrm{Au}(\mathrm{III})-\mathrm{QSA}$ and $\mathrm{Au}(\mathrm{III})-\mathrm{Q}$, can be used for spectrophotometric determination of gold. The reaction can be carried out in aqueous solutions (QSA as a reagent) as well as in methanolic-aqueous (1:1) ( $\mathrm{Q}$ as a reagent) solutions. The molar absorptivity at $\lambda_{\max }=291 \mathrm{~nm}$ equals to $2.2 \times 10^{4} \mathrm{~L} \mathrm{~mol}^{-1} \mathrm{~cm}^{-1}$ independently of the reagent used. The possibility of direct determination of gold in aqueous solutions with relatively high sensitivity is the advantage of the proposed method as compared with some methods developed earlier. ${ }^{30}$

The examined solutions obey Beer's law up $12 \mu \mathrm{g} \mathrm{ml}^{-1} \mathrm{Au}$. The calibration curve equations are: $y=0.1107 c+0.0213\left(R^{2}=\right.$ $0.9998)$ for QSA and $y=0.1155 c-0.009\left(R^{2}=0.9997\right)$ for $\mathrm{Q}$, where $y$ is the absorbance and $c$ is the concentration of gold. The RSDs of the determination of gold in the examined systems were in the ranges of $0.29 \%-1.04 \%$ and $1.22 \%-2.54 \%$, for QSA and Q, repectively (Table 2). The detection limit corresponds to $0.06 \mu \mathrm{g} \mathrm{ml}^{-1} \mathrm{Au}$ in both examined systems.

\section{The determination of gold in a cosmetic cream}

The methods developed for gold have been applied to the 
Table 2 Statistical data of the results of the determination of gold with quercetin and quercetin-5'-sulfonic acid

\begin{tabular}{|c|c|c|c|c|}
\hline \multicolumn{2}{|c|}{ 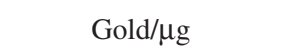 } & \multirow{2}{*}{$\begin{array}{c}\text { Standard } \\
\text { deviation/ } \\
\mu \mathrm{g}\end{array}$} & \multirow{2}{*}{$\begin{array}{c}\text { Relative } \\
\text { standard } \\
\text { deviation, \% }\end{array}$} & \multirow{2}{*}{ 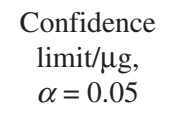 } \\
\hline Added & Determined $^{\mathrm{a}}$ & & & \\
\hline \multicolumn{5}{|l|}{ Q } \\
\hline 22.82 & 22.93 & 0.58 & 2.54 & $22.93 \pm 0.61$ \\
\hline 68.46 & 69.48 & 1.33 & 1.92 & $69.48 \pm 1.40$ \\
\hline 102.70 & 102.37 & 1.25 & 1.22 & $102.37 \pm 1.31$ \\
\hline \multicolumn{5}{|l|}{ QSA } \\
\hline 22.82 & 23.33 & 0.24 & 1.04 & $23.33 \pm 0.38$ \\
\hline 68.46 & 68.79 & 0.54 & 0.79 & $68.79 \pm 0.86$ \\
\hline 114.10 & 114.61 & 0.33 & 0.29 & $114.61 \pm 0.81$ \\
\hline
\end{tabular}

a. $n=6$.

Table 3 The effects of the chosen non-noble metals on the results of the determination of gold $\left(5.5 \mu \mathrm{g} \mathrm{ml}^{-1}\right)$ with $\mathrm{Q}$ and QSA

\begin{tabular}{|c|c|c|c|}
\hline \multicolumn{2}{|c|}{$\begin{array}{l}\text { Element/ } \\
\mu \mathrm{g} \mathrm{ml}^{-1}\end{array}$} & \multicolumn{2}{|c|}{$\begin{array}{l}\text { Au determined/ } \\
\qquad \mu \mathrm{g} \mathrm{ml}^{-1}\end{array}$} \\
\hline & & Q & QSA \\
\hline & 1.0 & 8.1 & - \\
\hline & 5.5 & 10.4 & 5.5 \\
\hline \multirow[t]{3}{*}{$\mathrm{Cu}(\mathrm{II})$} & 11.0 & 16.5 & 5.4 \\
\hline & 200 & 17.0 & 5.9 \\
\hline & 5.5 & 5.5 & 6.6 \\
\hline \multirow[t]{3}{*}{$\mathrm{Sn}(\mathrm{IV})$} & 11.0 & 5.6 & 6.9 \\
\hline & 200 & 6.0 & 4.4 \\
\hline & 5.5 & 5.9 & 6.2 \\
\hline \multirow[t]{3}{*}{ Ti(IV) } & 11.0 & 6.2 & 6.3 \\
\hline & 200 & 10.3 & 7.4 \\
\hline & 5.5 & 5.5 & 5.5 \\
\hline \multirow[t]{4}{*}{$\mathrm{Zn}(\mathrm{II})$} & 11.0 & 5.7 & 5.7 \\
\hline & 200 & 5.8 & 5.7 \\
\hline & 500 & 6.0 & 6.0 \\
\hline & 5.5 & 5.4 & 5.5 \\
\hline \multirow[t]{3}{*}{$\mathrm{Hg}(\mathrm{II})$} & 11.0 & 5.5 & 5.4 \\
\hline & 200 & 5.7 & 5.7 \\
\hline & 5.5 & 5.6 & 5.4 \\
\hline \multirow[t]{3}{*}{$\mathrm{Ni}(\mathrm{II})$} & 11.0 & 5.5 & 5.4 \\
\hline & 200 & 5.7 & 6.3 \\
\hline & 5.5 & 5.8 & 5.6 \\
\hline \multirow[t]{2}{*}{$\mathrm{Pb}(\mathrm{II})$} & 11.0 & 5.8 & 5.6 \\
\hline & 200 & 6.3 & 6.2 \\
\hline \multirow[t]{2}{*}{$\operatorname{Ag}(\mathrm{I})$} & 0.2 & $5.6^{\mathrm{a}}$ & 5.5 \\
\hline & 1.0 & - & $6.4^{\mathrm{a}}$ \\
\hline
\end{tabular}

a. Slight turbidity observed ( $\mathrm{AgCl}$ precipitation).

determination of the content of gold in a cosmetic cream. Metallic gold in the form of extremely thin $(0.1 \mu \mathrm{m})$ foil or gold powder is used for cosmetic purposes. Gold is supposed to prevent skin from aging owing to creating a conductive environment which enhances skin ability to absorb active ingredients contained in cosmetic products. ${ }^{34}$ Gold-containing cosmetics can enhance skin moisturizing effects, improve skin cells regeneration abilities and reduce wrinkles. Gold can affect the other active agents present in cosmetics. Our results show that gold converted into the ionic form $(\mathrm{Au}(\mathrm{III}))$ can affect the form of flavonoids that are often used as active cosmetic ingredients.

In this work the content of gold in Pulanna Gold Cream has been determined using the developed methods. The samples (1

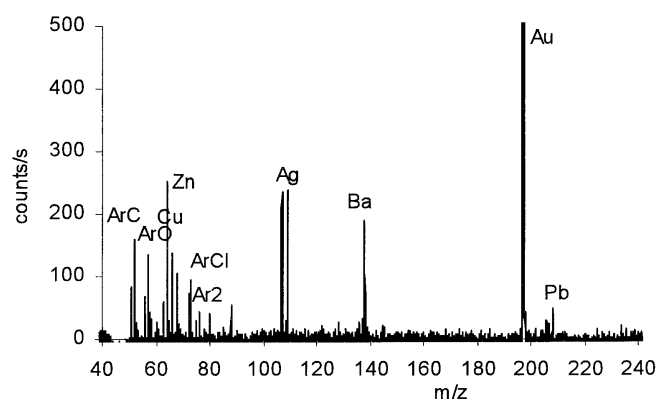

Fig. 2 ICP-TOFMS spectrum of the sample of the cosmetic cream examined.

$-2 \mathrm{~g}$ ) were put into the quartz crucible, first dried during $4 \mathrm{~h}$ at $110^{\circ} \mathrm{C}$ in a laboratory dryer, then submitted to burning on a gas burner for about $10 \mathrm{~min}$. The residue was dissolved in $4 \mathrm{ml}$ of aqua regia; then the excess of nitric acid was removed by the evaporation of the samples with three $1 \mathrm{ml}$ portions of conc. $\mathrm{HCl}$. The sample was dissolved and transferred into a $25-\mathrm{ml}$ volumetric flask using $0.1 \mathrm{M} \mathrm{HCl}$. A part $(2-4 \mathrm{ml})$ of the final solution was taken for individual spectrophotometric determination of gold using the procedures described above.

The detection of gold with the use of the developed methods has been conducted after the identification and evaluation of the concentrations of non-noble metals occurring in the examined samples. It is known that some non-noble metals can react with quercetin and QSA. In our work we have examined the effects of $\mathrm{Cu}(\mathrm{II}), \mathrm{Sn}(\mathrm{IV}), \mathrm{Ti}(\mathrm{IV}), \mathrm{Zn}(\mathrm{II}), \mathrm{Hg}(\mathrm{II}), \mathrm{Ni}(\mathrm{II}), \mathrm{Pb}$ (II) and $\mathrm{Ag}$ (I) on the determination of gold using both examined reagents. The obtained results are shown in Table 3. Copper(II) exhibits the highest effect on the determination of gold in the system $\mathrm{Au}(\mathrm{III})-\mathrm{Q}$. The increase in the results for gold of about $50 \%$ was observed at $1.0 \mu \mathrm{g} \mathrm{ml}^{-1} \mathrm{Cu}$ (II) in the examined solution $(\mathrm{Cu}(\mathrm{II}): \mathrm{Au}(\mathrm{III})=1: 5$ mass ratio). Significantly lower effects of the metals were observed when QSA was used as the reagent. The increase in the results of about $7 \%$ has been observed at $35-$ fold mass excess of $\mathrm{Cu}(\mathrm{II}): \mathrm{Au}$ in the examined solution. Zinc(II), $\mathrm{Hg}$ (II), $\mathrm{Ni}$ (II) do not affect the results for gold up to 2:1 mass ratio. QSA has been considered as more suitable for the determination of gold owing to lower interfering effects of non-noble metals. Additionally, as has been written above, QSA allows the determination of gold at room temperature and within a shorter reaction time.

For identification and evaluation of the amount of non-noble metals occurring in the examined cosmetic cream, the solutions obtained after the digestion procedure have been examined by ICP-TOFMS technique. Figure 2 shows a mass spectrum of one of the examined samples. Traces of $\mathrm{Cu}(<1 \mathrm{ppb}), \mathrm{Zn}(\mathrm{ca} .6$ $\mathrm{ppb}), \mathrm{Ag}$ (ca. $2 \mathrm{ppb}), \mathrm{Ba}(<1 \mathrm{ppb})$ and $\mathrm{Pb}(<1 \mathrm{ppb})$ were identified in the solutions submitted to ICP-TOFMS measurement (500-fold dilution coefficient applied). They corresponded to $<3, c a$. 30, ca. 10, $<4$ and $<2 \mu \mathrm{g} \mathrm{g}^{-1}$ of $\mathrm{Cu}, \mathrm{Zn}$, $\mathrm{Ag}, \mathrm{Ba}$ and $\mathrm{Pb}$ in dry samples, respectively. Such traces do not affect the results for gold when the solutions are examined by spectrophotometric methods. The $0.040 \pm 0.002 \%(n=6, \alpha=$ 0.05 ) of gold has been determined in the examined cosmetic cream using QSA as a reagent (Table 4).

Larger amounts of the interfering metals, if present in the examined materials, can be separated under nitric acid treatment introduced as an additional step into the sample preparation procedure. In our work, we have examined the effects of preliminary nitric acid treatment of the samples on the results 
Table 4 The results for the content of gold in the examined cosmetic cream

\begin{tabular}{cccc}
\hline \multicolumn{2}{c}{ QSA as a reagent } & \multicolumn{2}{c}{ Q as a reagent } \\
Sample/g & $\mathrm{Au}, \%$ & Sample/g & $\mathrm{Au}, \%$ \\
\hline 1.903 & 0.041 & 0.912 & 0.040 \\
1.988 & 0.041 & 0.952 & 0.042 \\
2.003 & 0.037 & 0.952 & 0.040 \\
2.017 & 0.040 & 1.096 & 0.045 \\
2.040 & 0.039 & 1.196 & 0.039 \\
2.191 & 0.042 & 1.209 & 0.044 \\
$\bar{x}=0.040 \%$, & & $\bar{x}=0.042 \%$, & \\
$s=0.002 \%, \mathrm{RSD}=4.83 \%$ & $s=0.002 \%, \mathrm{RSD}=5.81 \%$ \\
$\mu_{\alpha=0.05}=0.040 \pm 0.002 \%$ & $\mu_{\alpha=0.05}=0.042 \pm 0.002 \%$ \\
\hline
\end{tabular}

for gold. The dry residues obtained after burning the samples were treated with $4 \mathrm{M} \mathrm{HNO}_{3}$. The solutions were filtered off and gold was determined in the residue after treatment with aqua regia. In this case we have used quercetin for the detection of gold. The results $(0.042 \% \pm 0.002 \%$ Au $(n=6, \alpha=0.05$, $\mathrm{RSD}=5.8 \%)$ ) are in good agreement with those obtained when the samples were submitted to the detection of gold after direct treatment with aqua regia using QSA as a reagent (Table 4). No silver has been detected by ICP-TOFMS technique in the samples first treated with nitric acid.

\section{Conclusions}

Quercetin and its water-soluble derivative, quercetin- 5 '-sulfonic acid, undergo oxidation under the action of $\mathrm{Ru}(\mathrm{IV})$ or $\mathrm{Au}(\mathrm{III})$. No interaction of $\mathrm{Pd}, \mathrm{Pt}$ and Os with either examined reagents has been observed in chloride solutions examined. Ruthenium in the range of $0.11-30 \mu \mathrm{g} \mathrm{ml}^{-1}$ and gold in the range of $0.06-$ $12 \mu \mathrm{g} \mathrm{ml}^{-1}$ can be determined by using the amount of the generated oxidized form of the reagents $\left(\lambda_{\max }\right.$ at $\left.291 \mathrm{~nm}\right)$. Molar absorptivities are of $5.0 \times 10^{3}$ and $2.2 \times 10^{4} \mathrm{~L} \mathrm{~mol}^{-1} \mathrm{~cm}^{-1}$ for $\mathrm{Ru}$ and $\mathrm{Au}$, respectively. Simple and rapid methods for the determination of gold in a cosmetic cream have been developed. Gold $(0.04 \%)$ has been determined directly in the solutions obtained after digestion of the examined samples with aqua regia (QSA as a reagent) or using $4 \mathrm{M} \mathrm{HNO}_{3}$ treatment as an additional sample preparation step prior to dissolution of gold in aqua regia and detection with quercetin.

\section{Acknowledgements}

The authors express their gratitude to Dr. Elzbieta Skrzydlewska from Warsaw University of Technology for the ICP-TOFMS examination of the samples of a cosmetic cream.

\section{References}

1. J. B. Harborne and H. Baxter, "The handbook of natural flavonoids", 1999, Wiley, Chichester.

2. C. A. Rice-Evans and L. Packer, "Flavonoids in Health and Disease", 1998, Marcel Dekker, New York.

3. M. Katyal, Talanta, 1968, 15, 95.
4. M. Z. Gonzalez, M. E. Diaz Garcia, and A. Sanz-Medel, Talanta, 1989, 36, 919.

5. A. A. Y. El-Sayed, E. A. Saad, B. M. M. Ibrahime, and M. T. M. Zaki, Mikrochim. Acta, 2000, 135, 19.

6. Z. P. Want, L. L. Shi, G. S. Chen, and K. L. Cheng, Talanta, 2000, 51, 315.

7. A. M. Garcia-Campana, F. Ales Barrero, A. Lupianez Gonzalez, and M. Roman Ceba, Anal. Chim. Acta, 2001, 447, 219.

8. E. A. Saad, L. H. Khalil, M. T. M. Zaki, and A. A. Abu ElElla, Mikrochim. Acta, 2002, 140, 87.

9. M. Tarek, M. Zaki, A. K. Abdel-Kader, and M. M. Abdalla, Fresenius' J. Anal. Chem., 1991, 339, 197.

10. Y. X. Fan and Y. X. Zheng, Anal. Chim. Acta, 1993, 281, 353.

11. A. M. Jamaluddin and H. Jamal, Talanta, 1995, 42, 1135.

12. A. Y. El-Sayed and M. M. H. Khalil, Talanta, 1996, 43, 583.

13. N. Pourreza and K. Alizadeh, J. Anal. Chem., 1998, 53, 520.

14. H. Lian, Y. Kang, S. Bi, A. Yasin, D. Shao, Y. Chen, L. Dai, and L. Tian, Anal. Bioanal. Chem., 2003, 376, 542.

15. H. Z. Lian, Y. F. Kang, A. Yasin, S. P. Bi, D. L. Shao, Y. J. Chen, L. M. Dai, and L. C. Tian, J. Chromatogr. A, 2003 , 993, 179.

16. S. M. Z. Al-Kindy, F. O. Suliman, and S. B. Salama, Microchem. J., 2003, 74, 173.

17. A. Saffavi, M. Mirzaee, and H. Abdollahi, Anal. Lett., 2003, 36, 699.

18. L. E. Zel'tser, N. G. Vereshchagina, and A. V. Bychenko, Zh. Anal. Khim., 1991, 46, 2041.

19. O. A. Zaporozhets, L. S. Ivan'ko, I. V. Marchenko, and V. V. Sukhan, J. Anal. Chem., 2000, 55, 540.

20. O. A. Zaporozhets, L. S. Ivan'ko, I. V. Marchenko, E. V. Orlichenko, and V. V. Sukhan, Talanta, 2001, 55, 313.

21. F. Capitan, E. Manzano, A. Navalon, J. L. Vilchez, and L. F. Capitan-Vallvey, Talanta, 1992, 39, 21.

22. W. Szczepaniak and A. Szymański, Chem. Anal. [Warsaw], 1996, 41, 193.

23. L. C. Azeredo, M. A. A. Azeredo, R. N. Castro, M. F. C. Saldanha, and D. V. Perez, Spectrochim. Acta, Part B, 2002, 57B, 2181.

24. M. Kopacz, J. Anal. Chem., 2003, 58, 225.

25. M. Kopacz and D. Nowak, Microchem. J., 1993, 47, 338.

26. M. Kopacz and D. Nowak, Polish J. Chem., 2000, 74, 303.

27. M. Kopacz, B. Bujonek, D. Nowak, and S. Kopacz, Chem. Anal. [Warsaw], 2001, 46, 621 .

28. M. Balcerzak, Anal. Sci., 2002, 18, 737.

29. S. I. Ginsburg, N. A. Ezerskaya, I. V. Prokof'eva, N. F. Fedorenko, V. I. Shlenskaya, and N. K. Belskii, "Analytical Chemistry of Platinum Metals", 1972, Nauka, Moscow.

30. Z. Marczenko and M. Balcerzak, "Separation, Preconcentration and Spectrophotometry in Inorganic Analysis", 2000, Elsevier, Amsterdam.

31. M. T. Golovkina, S. V. Karavan, and M. V. Pokrovskaya, Zh. Obshch. Khim., 1974, 44, 2569.

32. M. Kopacz and D. Nowak, Zh. Obshch. Khim., 1991, 61, 1361.

33. M. Balcerzak, Crit. Rev. Anal. Chem., 2002, 32, 181.

34. X. X. Shu, L. Zhang, and S. B. Liu, Biuletyn Kosmetologiczny, 1998, 2, 87. 